\title{
Sixth Grade Teachers' Conceptions of Classroom Assessment
}

\author{
Sethusha Mantsose Jane \\ Department of Teacher Education \\ University of South Africa
}

\begin{abstract}
This paper explored conceptions that sixth grade teachers hold about classroom assessment and how these conceptions influence their classroom assessment practices. The research was qualitative in nature and employed an instrumental case study approach. Semi-structured interviews, observations and document analyses were used. The study utilized Brown's [4] conceptual framework on conceptions of assessment. The findings reveal that teachers' conceptions of assessment are influenced by the social and education context in which they find themselves and that their personal experiences of assessment also influence their conceptions of assessment.
\end{abstract}

\section{Introduction}

Assessment is considered to be one of the key processes in the teaching and learning cycle as it provides important decision-making information to teachers in the classroom (Department of Education, [9]. Information obtained from assessment can be used to evaluate and improve learning and instruction. Much of the classroom assessment literature is of what teachers do, or what they should do, what kinds of information they should gather and to what uses they should put the information (Brown \& Hirschfield, [2]; Harris \& Brown, [11]; Kotze, [15]; Peterson \& Irving, [17]. There is limited research on how sixth grade teachers conceptualize assessment in the South African context, and what kinds of assessment methods and tools they actually use in their classrooms to assess learners. Furthermore, the question arises as to how such conceptions of assessment influence teachers' classroom practice. On the basis of assumptions that conceptions are dynamic, contextual, and best revealed through in-depth investigation (Brown, [3]), this paper seeks to answer these questions in the teachers' own voices, through interviews of teachers from two different schools.

Existing research has also focused on the various forms of assessment purpose (Chetcuti, Murphy \& Grima [7]), use of them (Smith \& Gorard [18]), assessment practices in science and mathematics (Meier, Rich \& Cady [16]), and assessment systems in various countries (Brown, [5]). This paper takes these issues further by exploring sixth grade teachers' conceptualization of assessment and whether these conceptions might in some way give an indication about how some teachers' classroom practices might be contributing to improving teaching and learning and improving trends in student performance.

Teachers may be contributing positively to educational improvements, but in ways not usually recognized as 'good practice' (Akyeampong, Pryor and Ampiah, [1]). Others may be adopting unsatisfactory approaches that could be attributed to weaknesses in professional support (e.g. lack of continuous development opportunities) (Kahn, [14]). Unless one interrogates teachers' understanding of assessment practices from instances within their own context, and gain their viewpoint as to how these accomplish desirable learning, one may only draw superficial conclusions about their competence and understand little about how to improve less effective teachers. Gaining a deeper understanding of teachers' classroom assessment conceptions require analysis based on reflections of specific encounters with teachers in teaching and learning scenarios.

\section{Conceptual Framework}

This article utilizes the conceptual framework based on the work of Brown [4]. In this conversation, four major conceptions about assessment are exhibited; (1) assessment is related to improvement of learners' learning and teachers' teaching, (2) assessment certifies that learners have learned or met standards, (3) assessment evaluates the quality of schools and teachers, and (4) assessment is irrelevant to the work of teachers.

Based on the literature reviewed (Brown) [2-5], (Harris and Brown) [11] and (Brown and Hirschfield) [2] the four major conceptions are used as filters through which teachers interpret and experience state sponsored or school-wide policies and practices related to assessment. It is appropriate to investigate how teachers conceive of assessment and how their different conceptions influence their classroom assessment practices in order to get a fuller understanding of what assessment means to teachers in a South African context. 


\section{Research method}

The research was conducted in two primary schools in one city in South Africa. I focused on grade six in the intermediate phase and used a variety of data including in-depth semi-structured interviews, classroom observations and analysis of key documents (learners' books, teachers' assessment documents. The interview schedule comprised of questions on teachers' own understanding and experiences of classroom assessment. Observations of teaching and assessment practices were conducted over a four-week period with each teacher. The observations were followed by interviews and these provided teachers with an opportunity to share their understanding and experiences.

\section{Research Findings}

\subsection{Understanding teachers' conceptions of assessment:}

\section{Case study one}

Malebo Mathabe "Without assessment teaching would be pointless"

Malebo Mathabe was a 32 year old Black African female teacher at Bojanala Primary School, a predominantly Black school situated Motsoseng, a Black township situated east of Pretoria, South Africa. She graduated with a bachelor's degree in Education Management from UNISA in 2000, specializing in Education and Psychology. During her university years she was assessed through tests, projects and assignments.

Malebo did not receive any training on assessment during her university studies. She gained much assessment knowledge from an Assessor Training Course that she completed in 2007, organized by the Skills Education and Training (SETA). However, this training did not focus on classroom-based assessment but rather on the general aspects of assessment in a broader context. The training was conducted within a week. Malebo had also attended a one-week RNCS workshop in 2003, organized by UNISA.

Malebo's training needs were largely on assessment methods. She felt she used only a few assessment methods and would like to explore more. "Quite often as teachers, we kind of rush to conclude that learners cannot achieve in class, when we have not explored the different assessment methods to see which ones work with certain children. We do not assess the same way and we also do not assess the way we should. I think in most cases, children do not have problems, the problems lie with our own methods of teaching and assessment".

In explaining her understanding of assessment Malebo indicated the purpose of assessment:

"We need to assess in order to know how learners understood what has been taught and whether there is progress in learning. Assessment is important to indicate what the learners have been taught and what they know".

By comparing her response to the assessment definition as outlined in the National Policy on Assessment (DoE, [7]), I would argue that Malebo had a surface understanding of the definition of assessment. However, the key aspects that she mentioned in her definition were progress and learners' learning. Malebo indicated that she used continuous assessment throughout:

"I teach them today, and the next day I revise the work and give them an assessment activity. When it is a double period, I teach them in the first period and assess them in the next".

This response reveals a profound understanding of continuous assessment as compared to the assessment policy. The policy does not state that learners should be assessed immediately after teaching, but rather on an ongoing basis (DoE, 2007:18). Furthermore, assessment is not a separate entity from teaching and learning.

Malebo indicated in the interview that she used the learning programmes, work schedules and lesson plans that she found at the school, but in most instances she used her own knowledge and experience to prepare for lessons for her class. However, during my observations I noticed that there was no record of the learning programme that she said had been provided by the Department of education. The work schedule covered the content and topics, learning outcomes, assessment standards, context, resources, assessment and duration. The lesson plan was not clear at all. It appears from the lesson plan that Malebo did not understand how to write one as stipulated by the NCS, nor understand what 'context' meant. The aspects that she listed under 'context' referred to skills that learners would have achieved at the end of the lesson.

A number of factors hindered her classroom assessment practices:

"In my previous school, I used to take children outdoors, to perform activities and we used to take teaching aids and equipment to explore outside. Learners would bring other materials from home and we designed Math teaching and learning aids. I 
cannot do that at this school. Learners do not bring anything from home even when I write letters to parents to request them to support their children".

Another challenge that Malebo also identified was overcrowding, which hampered her progress in assessment because she had to mark 46 books each day and assess the learners individually.

Malebo used peer assessment in the speed test. Learners in her class wrote a summative test at the end of the term, the purpose of which for her was to know how well learners understood the term work and to identify any gaps in their understanding. The test was administered like an examination, taking the form of a paper-and-pencil test, where learners were required to write answers in the spaces provided on the examination paper.

Malebo recorded all assessment tasks, indicating that she recorded the marks immediately after marking. However, Malebo did not consider homework for assessment. After every assessment task she made learners aware of their strengths and weaknesses. In this way she could identify learners with barriers to learning, an important aspect of Inclusive Education.

Parental involvement at her school was minimal. Some parents were not aware of anything that happened in the school and as such could not support their children. Parents had been informed and agreed to pay school fees but they did not fulfill their obligations. The school was static financially, with photocopiers dysfunctional and irreparable because of lack of finances.

Malebo indicated that once during the year a group of officials from the district visited the school in order to conduct monitoring. They spent just one day in the school and only checked the teachers preparation files. The Heads of Department at the school were also supposed to check the teachers' work but did not do so. The learning area specialists had visited the school recently and discussed the schools' assessment plan with the teachers, but they concentrated on one learning area and checked the teachers' file as well as the learners' work.

Malebo had two learners who had reading barriers. They could not read even when she tried hard to support them. She discussed the matter with the parents and together they developed strategies for intervention. Malebo gave the parents some extra reading activities to assist them, and as time went on she noticed that those learners' reading had improved.

A number of pertinent findings emerged from the narrative case of Malebo Mathabe. First, it was evident that Malebo had gained much assessment knowledge through experience. Her experiences of previously working at a well-resourced school contributed to her assessment practices at her present school. Second, she found it hard to adjust to her current school due to unavailability of resources, lack of support from learning area specialists, lack of parental involvement, absenteeism of learners and lack of teacher commitment, and these impeded on her assessment practices. Third, she preferred to use tests, class activities, and projects to assess learner performance. She appeared not to have any knowledge of informal assessment, hence her lack of knowledge about rubrics and checklists. Fourth, she relied on textbooks for her assessment tasks.

Malebo's conceptualization of classroom assessment could be summarized as follows: assessment requires parental involvement and provision of expanded opportunities, implying the teachers' self reflection and self evaluation; peer assessment is important; assessment means progression in learning; learners' understanding of what has been taught is important; and assessment is evidence of learners' work.

The next section looks into Patricia Petersen's conceptions and understanding with regard to classroom assessment and the way she proceeds to implement this in her actual classroom practice.

\section{Case study two}

Patricia Petersen "Through assessment I am able to reflect on my teaching"

Patricia Petersen was a 48 year old teacher at MJ Smith primary school, a school situated in Hoogte, Pretoria, South Africa. She completed her three-year teachers' diploma in East London in 1985. In her training Patricia did not receive any specific training on assessment. The assessment during her time was through end-of-term tests, going out to schools for teaching practice, to be assessed by lecturers on a day-to day basis. Even though assessment was based on strengths and weaknesses of students, it was conducted in a very strict manner. They were assessed on how to teach large classes as well as to approach difficult class situations. Their assessments were also based on assignments, mostly topics to discuss and include in written reports to be sent in. As such they were compelled to visit libraries to access extra reading material. Assessments were also in the form of examinations.

At the commencement of this research, Patricia was in her $27^{\text {th }}$ year of teaching, but had been in this school since 2005. She had taught Grades 5, 6 and 7 and was currently teaching Grade 6. She had received in-service training from the Department of Education for the learning areas that she taught. During the training, she was motivated to do projects and assignments related to Arts and to Culture and Technology, and to relate these with the developmental level of the learners. When they dealt with assessments it was learning area-specific and 
not applicable to all learning areas. She attended at some point a workshop conducted by Classmart, an educational publisher, curriculum implementation and teacher training company. She had since discovered that their resource packs were easy to use. Patricia did not attend any Outcomes-Based Assessment workshop. She learnt about assessment through discussions with other teachers in her school and in district and cluster meetings. She felt that her training needs were on the policy on assessment as she did not understand the different levels of planning, the learning programme, work schedule or lesson plan. She also felt she needed training on Inclusive Education as she had experienced learners with learning barriers in her class. These learners could not read or spell correctly, and some could not listen attentively in class. She needed training on how to improve learners' skills of research, reading and writing.

In explaining assessment, Patricia referred to the importance of assessment on the side of the teacher:

"It is a way of understanding how you cope with the work assigned to you as a teacher. It is a way of seeing whether you are following the correct way of assessing the child and how such assessments benefit the child. It is also a way of checking whether you as a teacher are fair to the children, the question papers that you set, are they reasonable for a particular grade and relevant to the learning area. Through assessment I am able to reflect on my teaching, how did I present the work, do the children understand and whether I need to change my teaching style”.

It is apparent from her definition of assessment that she perceived the main purpose of assessment as improving teaching. This meant that Patricia saw assessment as the foundation for effective teaching. She assessed the quality of her teaching by using the assessment information gathered during each lesson presentation or activity that she conducted. Through assessment she could adjust or modify her teaching appropriately, thereby improving on her teaching efforts.

Patricia was convinced that the assessment policy would make a difference to the way learners were taught at her school if the teachers understood and interpreted it well. She indicated that the policy was important as it specified guidelines to be followed in assessing learners. Patricia mentioned that she tried very hard to keep her assessments in line with the policy.

Patricia was aware of the existence of the National Assessment Policy, and that she had to use it for planning. She had copies of the learning programme, the work schedule and the lesson plans provided by the Gauteng Department of Education.
She also referred to textbooks for activities to compile assessment tasks. The work schedule specified the learning area, grade, duration, learning outcomes and assessment standards, core knowledge, integration, resources, activities and assessment. She mentioned that it was important for planning and preparation of assessment. Patricia also had lesson plans for Arts and Culture and for Technology for the whole year. Each lesson plan clearly explained the learning outcomes, assessment standards and the activities that learners were expected to do in order to achieve the learning outcomes. They also incorporated the knowledge, skills, attitudes and values that learners were required to attain.

I had noticed during my lesson observations that Patricia did not refer to the learning programme, the work schedule or the lesson plans in any of her lessons, even though she had mentioned them in the interview. When I asked her about this in one of the interviews she indicated that these were prescribed by the department and not 'user-friendly'. She preferred to use the resource pack from Classmart, which provided Learner Teacher Support Material containing teacher and learner guides used by over 350 schools in the province. I went through the teacher's guides and my initial impression was that the Classmart resource packs generally appeared to be NCS-compliant in-service training guides for primary school teachers. The teachers' guide provided a combined learning programme and work schedule, lesson plans, resources, teaching techniques and memoranda.

In the learners' guides the skills and knowledge components for the learners were well-structured and presented in a constructive and practical way. Comprehensive rubrics were used and it was clear that attention was given to the language correctness, clear presentation and good graphics of the product.

I chose to focus on one lesson plan in order to understand how Patricia conceptualized planning in assessment. The lesson plan reflected what she had claimed during the interviews. However, I noticed that during the lesson presentations Patricia did not refer to this lesson plan to check what needed to be done. The actual activities that she did in class were not reflected on this lesson plan. What appeared to be similar between her lesson presentation and lesson plan were the forms and tools of assessment. This suggested that Patricia did not clearly understand planning in assessment and so could not relate planning or implementation.

There was an internal assessment policy at her school which clearly described what was expected from each teacher. Each learning area had its own assessment policy, which outlined how many assessment tasks had to be written and how many had to be recorded. The Heads of Department within the school were responsible for ensuring that the policy was implemented. 
Patricia preferred to use examination for the formal assessment as well as projects for her Arts and Culture and Technology learning areas. Before giving learners a project she explained firstly what the project was about and how learners were expected to carry it out. Learners were required to research a particular project before doing it. She highlighted that in these learning areas learners learned by research through exploring, investigating and discovering. Learners were also engaged in designing projects as well as in writing out projects. In writing out projects, learners' writing and presentation skills were assessed. This assessment catered for the different learners, viz. those who were good in writing and those who were good at designing. She also gave learners class work and assignments, but clarified these beforehand. She believed it was important to explain thoroughly how to investigate, as well as how to write reports.

Patricia gave learners four assessment tasks and one test per term. The test was regarded as summative evaluation. She used rubrics for the assessment tasks and a memorandum for the test, and continuous assessment in projects and assignments. When she gave an assignment or a project she used to check the learners' progress with the task to identify the problems that they experienced as well as the progress they made from time to time. In this way she was able to see if the learners had interpreted the task correctly and assisted where necessary.

I had an opportunity to look at the learners' books and portfolios, and what I observed confirmed what Patricia had indicated in the interview. Learners' books revealed the class work and written assignments that she had given them and in the portfolios were all assessment tasks.

Patricia also used peer assessment because she believed it to be beneficial for the learners. She had realized that some in her class had language barriers. They could not express themselves clearly in English, and so felt more comfortable during peer assessment as they were in most cases too shy to open up to her as a teacher but could talk to their peers:

"I like it because it provides an opportunity to teach them to be objective, to develop trust in each other and to engage in discussions. In this way I teach them to be honest, to give credit to good work. I usually group them, I take the brighter learners to be the group leaders and in most cases they rotate. It teaches them leadership skills as well”.

Patricia emphasized that peer assessment created a more relaxed atmosphere in her class. She had observed that learners were free to interact with each other, and that the results of peer assessments were positive. She communicated assessment criteria to learners and believed it was important that learners were clear as to what was expected from them. To this end she also explained the rubrics well in advance.

On the question of the factors that hindered her assessment practices, Patricia indicated that the language barrier was the greatest challenge in her class, and that she had realized through discussions with other teachers that this was the case in all the classes. She highlighted that about 90 percent of the learners in the school were Afrikaans speaking, which created confusion because the home language was different from the Language of Learning and Teaching, which was English.

Another challenge she had encountered related to the Technology projects, with some learners not having television sets at home and so not being familiar with machines for road construction, booms or large trucks. Patricia wished that parents had been supportive so as to help her in bringing the world to the classroom.

Patricia indicated that she recorded all assessment tasks as well as the test. After marking the learners' books, she gave feedback, which gave her an idea of whether the learners understood the assessment task. Through these discussions learners saw their mistakes and made corrections, which she regarded as a form of reflection on her part. She also made learners aware of their strengths and weaknesses, giving them rubrics and explaining these clearly. For the children who did not do well in an assessment task Patricia organized individual discussions with them.

Patricia expressed concern that the district officials did not seem to be sure of what they were doing. They had shifted their responsibilities for supporting schools to cluster leaders. The learning area specialists addressed teachers at cluster meetings and not in schools. Patricia was concerned that the information from the cluster leader and the department was contradictory. Most of the time she was confused and frustrated because of the information she received from the cluster:

"I wish we could have a clear directive from the department and that the district officials become responsible for support to schools, not the cluster leaders. By the way cluster leaders are teachers like us, how can they become experts or specialists and do the work that has to be done by the experts”?

Lack of parental involvement was a cause of great concern at her school, and Patricia highlighted that parents were not generally supportive. She regarded learning as an important aspect of children's lives with partnership of utmost importance. However, she struggled most of the time to get parents to come to school, even when requested to. 
Patricia was pleased that at her school there was a monitoring mechanism. The Head of Department (HoD) regularly checked her work and gave prompt feedback, checking her entire file and then compiling reports to the principal about each aspect of her work with suggestions for improvement. Patricia provided me with a copy of the internal moderation report from her HoD. After the HoD had checked her file it was sent to the cluster leaders and finally to the learning area specialist, a process that took place only once a term. It was only when the learning area specialist detected problems with the work that they would visit the school. The district officials had encouraged teachers to attend the cluster meetings because they saw it as an opportunity for teachers to engage with the policy and its requirements. The teachers were also able to share good practices from their schools with their counterparts.

Patricia emphasized that as staff they regularly held meetings to discuss assessment. This also happened within the different learning areas. All teachers benefited from the discussions because they shared ideas and good practices.

A number of pertinent findings emerged from the case of Patricia Petersen. First, she admitted having the NCS document but showed no understanding of the different levels of planning as set out in the NCS policy document. She also did not seem to have an understanding of the principles of Inclusive Education. Second, she regarded self-reflection as an important aspect in assessment and also as a foundation for effective teaching. However, she expressed concern that most teachers did not care about the quality of education, hence their lack of commitment to teaching. Third, she raised concerns that the Department of Education (DoE) was not doing enough in terms of teacher in-service training, but rather they outsourced such training to Non Governmental Organizations (NGOs) and training institutes outside the department. Fourth, the issue of language in assessment was a point of concern since learners were assessed in English and not in their mother tongue. Fifth, she regarded learning programmes, work schedules and lesson plans supplied by the DoE as not being easily accessible to the learners, hence she preferred the materials from a training company. Monitoring mechanism at her school was conducted satisfactorily. She also identified lack of support from learning area specialists. She preferred to use summative assessment.

Patricia's conceptualization of classroom assessment could thus be summarized as follows: self-reflection is important in assessment; what the teacher wants to assess has to be communicated beforehand; learners' developmental level needs to be taken into consideration when preparing assessment tasks; assessment has to be fair and objective; revision of work has to be done before assessment; and peer assessment is important as it teaches learners to be accountable and objective.

\section{Discussion and Conclusion}

Based on the evidence gleaned from the study, I posit that to understand assessment from the teachers' perspectives it is necessary to understand the beliefs (Calderhead) [6] with which they define their work. The beliefs teachers held influenced their perceptions and judgments, which in turn affected their behavior in the classroom (Brown, [5]. The interaction of beliefs and practices therefore had strong implications for teaching and learning.

Gipps, Brown, McCallum and McAlister [10] categorized teachers' conceptions according to intuitives (assessing without written work), gatherers of evidence (collected written records to demonstrate learners achievement) and systematic planners (plans for shaping instruction). The findings suggest that teachers were not intuitives, as it is evident from the data presented and discussed that they used written work to assess learners. I surmise that they can be seen as gatherers of evidence, because they assessed through tests, reading, class work, spelling, speed tests, monthly and term tests.

Hill [12] clearly related to Gipps et al.'s [12] categorization of teachers' conceptions and highlighted that teachers were either unit assessors, head note assessors or integrated systematic assessors. Based on the explanations of these categories, I strongly feel that Malebo and Patricia portrayed themselves as unit assessors. This is because they put extreme emphasis on recording and reporting, a conception linked to school accountability. They reported learner progress formally on achievement of learning outcomes at the end of each unit of instruction.

Stamp [19] identified three major conceptions of assessment, namely assessment caters for needs of individual learners, assessment blocks teacher initiatives, and assessment looks at traditional summative examination. The findings in this paper reveal that assessment caters to a larger extent for needs of individual learners in the sense that teachers used assessment as a diagnostic tool, to identify learners' strengths and weaknesses and their barriers to learning and development. Malebo and Patricia also referred to expanded opportunities and to the use of variety of assessment strategies to assess learners. It is also evident that they interpreted assessment as blocking their initiatives. They felt they had to assess according to policy prescriptions, for example the policy prescribed how many assessment tasks had to be conducted and recorded. They assessed because they had to comply with policy requirements, even when they felt this was against their beliefs. The two teachers practiced and preferred traditional summative examination. They 
argued that this reflected the overall learner performance. I suggest that this is because they had as students been exposed to this type of assessment, implying that their background and personal experiences played a significant role in their assessment practices.

This paper shows that teachers' conceptions of assessment are affected by pressures such as overcrowding, compliance, time management, policy interpretation and implementation, parental involvement, extra administrative workload and paperwork, support from the departmental officials, training and resources. As Harris and Brown [11] discovered, these multiple tensions create a much more complex teaching thinking space than the simple dichotomy.

Data gleaned from this study also reveals that Malebo and Patricia used a variety of assessment types for a range of purposes, some of which were more aligned with their personal opinions about best assessment practice. They indicated that their students were their first priority, which led them to reject or ignore mandated assessment practices that they deemed inaccurate (based on their personal knowledge of the learners' abilities) or negative for students. This is consistent with the child-centred pedagogy imbued in teacher practice in New Zealand Hill and Tyson, [13].

Notwithstanding the data from a small sample of two teachers from two different environments, the pattern of conceptions revealed is consistent with previous studies with teachers in different phases and levels of schooling, and in different learning areas (Department of Education, [8]. However, the most important point to be made here is that, from the data, more focus was on the improvement and school accountability conceptions and less on student accountability and irrelevance. It would also seem that the teachers were still using largely traditional conventional modes of assessment.

\section{References}

[1] Akyeampong, K., Pryor, J. \& Ampiah, J.G. (2006). A vision of successful schooling: Ghanaian teachers' understanding of learning, teaching and assessment. Comparative Education, 42 (2) pp155- 176.

[2] Brown, G.T. L \& Hirschfield, G.H.F. (2008). Students' conceptions of assessment: Links to outcomes Assessment in Education: Principle, Policy and Practice, Vol. 15, No. 1: 3-17.

[3] Brown, G.T.L. (2002). Teachers' conceptions of assessment. Validation of an abridged instrument. Psychological Reports, 99: 166-170.

[4] Brown, G.T.L. (2003). Teachers' instructional conceptions: Assessments' relationship to learning, teaching, curriculum and teacher efficacy. Paper presented at the joint conference of the Australian and New Zealand Associations for Research in Education (AARE/NZARE), Auckland, 28 Nov. - 3 Dec.

[5] Brown, G.T.L. (2004). Teachers' Conceptions of Assessment Implications for Policy and Professional Development. Assessment in Education: Principles, Policy and Practice, 11 (3): 301-318.

[6] Calderhead, J. (1996). Teachers: beliefs and knowledge. In Berliner, D \& Calfree, R (Eds.), Handbook of educational psychology, 709-725, New York: Macmillan.

[7] Chetcuti, D., Murphy, P. \& Grima, G. (2006). The formative and summative uses of a Professional Development Portfolio: a Maltese Study. Assessment in Education, 13 (1) 97-112.

[8] Department of Education, (2002). Revised National Curriculum Statement R-9 (Schools). Pretoria: Department of Education.

[9] Department of Education, (2007). National Policy on Assessment and Qualifications for Schools in the General Education and Training Band. Government Gazette, 500 (29626). Pretoria.

[10] Gipps, C., Brown, M., McCallum, B \& McAlister, S. (1995). Intuition or evidence? Teachers and national assessment of seven-year-olds. Buckingham, UK: Open University Press.

[11] Harris, L. \& Brown, G.T.L. (2008). New Zealand teachers' conceptions of the purpose of assessment: Phenomenographic analyses of teachers' thinking. Paper presented to the Australian Association for Research in Education (AARE) Annual Conference, Brisbane, Australia.

[12] Hill, M.F. (2000). Remapping the assessment Landscape: primary teachers reconstructing assessment in self-managing schools. Unpublished PhD Thesis, University of Waikato, Hamilton, NZ.

[13] Hill, N.E. \& Tyson, D.F. (2009). Parental Involvement in Middle School: A Meta-Analytic Assessment of the Strategies that promote achievement. Development Psychology. American Psychological Association, Vol. 45, No. 3: 740-763.

[14] Kahn, E.A. (2000). A Case Study of Assessment in a Grade 10 English Course. The Journal of Educational Research, 93: 276- 286.

[15] Kotze', G.S. (2002). Issues related to adapting assessment practices. South African Journal of Education: EASA Science Africa, Vol. 22 (1): 76-80.

[16] Meier, S., Rich, B. \& Cady, J. (2006). Teachers' use of rubrics to score non-traditional tasks: factors related to discrepancies in scoring. Assessment in Education: Principles, Policy and Practice, 13 (1): 69-95.

[17] Peterson, E.R. \& Irving, S.E. (2007). Secondary school students' conceptions of assessment and feedback. 
Learning and Instruction. Elsevier Vol. 18, Issue 3: pp. 238-250.

[18] Smith, E. \& Gorard, S. (2005). 'They don't give us our marks': the role of formative feedback in students' progress. Assessment in Education: Principles, Policy and Practice,

12 (1): $21-38$.

[19] Stamp, D. (1987). Evaluation of the formation and stability of student teacher attitudes to measurement and evaluation practices. Unpublished doctoral dissertation, Macquarine University, Sydney, Australia. 